\title{
Albumin-based nanoparticles: a promising strategy to overcome cancer drug resistance
}

\author{
Islam Hassanin ${ }^{1,2}$, Ahmed Elzoghby ${ }^{2,3}$ \\ 'Department of Biotechnology, Institute of Graduate studies and Research, Alexandria University, Alexandria 21526, Egypt. \\ ${ }^{2}$ Cancer Nanotechnology Research Laboratory (CNRL), Faculty of Pharmacy, Alexandria University, Alexandria 21521, Egypt. \\ ${ }^{3}$ Department of Industrial Pharmacy, Faculty of Pharmacy, Alexandria University, Alexandria 21521, Egypt.
}

Correspondence to: Dr. Ahmed Elzoghby, Department of Industrial Pharmacy, Faculty of Pharmacy, Alexandria University, Alexandria 21521, Egypt. E-mail: aelzoghby@bwh.harvard.edu

How to cite this article: Hassanin I, Elzoghby A. Albumin-based nanoparticles: a promising strategy to overcome cancer drug resistance. Cancer Drug Resist2020;3:930-46. http://dx.doi.org/10.20517/cdr.2020.68

Received: 20 Aug 2020 First Decision: 23 Sep 2020 Revised: 28 Sep 2020 Accepted: 9 Oct 2020 Available online: 3 Nov 2020

Academic Editor: Vladimir P. Torchilin Copy Editor: Cai-Hong Wang Production Editor: Jing Yu

\begin{abstract}
Circumvention of cancer drug resistance is one of the major investigations in nanomedicine. In this regard, nanotechnology-based drug delivery has offered various implications. However, protein-based nanocarriers have been a versatile choice compared to other nanomaterials, provided by their favorable characteristics and safety profiles. Specifically, albumin-based nanoparticles have been demonstrated to be an effective drug delivery system, owing to the inherent targeting modalities of albumin, through gp60- and SPARC-mediated receptor endocytosis. Furthermore, surface functionalization was exploited for active targeting, due to albumin's abundance of carboxylic and amino groups. Stimuli-responsive drug release has also been pertained to albumin nano-systems. Therefore, albumin-based nanocarriers could potentially overcome cancer drug resistance through bypassing drug efflux, enhancing drug uptake, and improving tumor accumulation. Moreover, albumin nanocarriers improve the stability of various therapeutic cargos, for instance, nucleic acids, which allows their systemic administration. This review highlights the recent applications of albumin nanoparticles to overcome cancer drug resistance, the nanofabrication techniques, as well as future perspectives and challenges.
\end{abstract}

Keywords: Albumin, active targeting, cancer therapy, drug delivery, multi-drug resistance, nanoparticles, stimuliresponse release, nucleic acid therapy 


\section{INTRODUCTION}

Cancer is the uncontrolled proliferation of abnormal cells, which can be treated by various strategies ${ }^{[1-3]}$. Surgery, radiotherapy, hormone therapy, targeted drug therapy, chemotherapy, and immunotherapy are successful therapeutic options for many patients. However, resistance to these treatments may develop, especially for chemotherapy, which may compromise the efficacy of cancer treatment ${ }^{[4,5]}$.

Multiple mechanisms participate in the development of cancer resistance [Figure 1]. Intrinsic factors may include: (1) genetic variations, which are comprised of gene mutations, amplifications, deletions, or alterations of miRNA; and (2) epigenetic variations, which are attributed to transcriptomic or proteomic variations. Extrinsic factors are related to $\mathrm{pH}$, hypoxia, and interaction with other tumor cells. Collectively, these factors contribute to the heterogeneity of tumors ${ }^{[3]}$. Moreover, drug inactivation, drug efflux, reduced drug uptake, resistance to apoptosis, enhanced DNA repair mechanisms, and immunosuppression and immune evasion are cancer resistance mechanisms which may negatively influence anti-cancer drug treatment ${ }^{[6-8]}$.

Several strategies have been proposed to overcome acquired cancer resistance mechanisms, including knocking-down of genes responsible for resistance, drug efflux inhibitors, bypassing drug uptake and drug efflux by receptor-mediated endocytosis ${ }^{[9]}$, utilizing stimuli-responsive drug carriers ${ }^{[10,11]}$, or targeting multiple pathways through combination treatments ${ }^{[12,13]}$. These strategies may be implemented via nanotechnology-based delivery systems. Nanocarriers may offer several advantages, such as combined drug use, passive and active targeting, enhanced tumor accumulation, overcoming poor pharmacokinetic profiles of the anticancer agents, improving the stability of the loaded cargo, and tuned drug release profiles ${ }^{[14-16]}$.

Protein nanocarriers, especially albumin-based nanoparticles, offer multiple advantages compared to other nanomaterials. Biocompatibility, biodegradability, less immunogenicity, and lower cytotoxicity are favorable characteristics of protein nanocarriers ${ }^{[17]}$. Moreover, proteins possess an intrinsic ability to target tumor cells, either passively or actively, through overexpressed receptors. Functional groups, necessary for functionalization with targeting materials or active therapeutics, are available for various proteins ${ }^{[18,19]}$.

Albumin-based nanocarriers are a versatile choice, implemented to overcome drug resistance mechanisms for multiple types of tumors. Albumin nanoparticles can be synthesized utilizing various approaches ${ }^{[20]}$, and they offer significant implications including passive and active targeting ${ }^{[21,22]}$, controlled drug release, and, more importantly, bypassing cancer drug resistance mechanisms, such as poor drug uptake or drug efflux mechanisms, as well as inhibition of apoptosis. This review highlights the recent methodologies for the fabrication of albumin-based nanoparticles, application of these nanoparticles in overcoming cancer drug resistance, and future perspectives and challenges.

\section{ALBUMIN}

Human serum albumin (HSA) is a globular plasma protein, which is comprised of 585 amino-acids, and possesses a molecular weight of 66,500 Dalton $(\mathrm{Da})^{[23,24]}$. HSA is composed of three homologous domains, forming a heart-shaped molecule. It is stable against a wide range of factors including temperature, $\mathrm{pH}$ (4-9), and organic solvents. Bovine Serum Albumin (BSA) possesses a molecular weight of 69,323 Da. BSA has gained considerable attention in the pharmaceutical industry, owing to low cost, high abundance, and ease of purification. However, compared to HSA, BSA may induce unfavorable immunogenic reactions ${ }^{[25,26]}$.

Albumin is a versatile biomaterial for synthesis of nanoparticles (NPs) ${ }^{[27]}$. The efficiency of the albuminbased delivery resides in its ability to enhance tumor targeting and accumulation. For instance, enhanced tumor accumulation is due to the enhanced uptake passively mediated by the enhanced permeability and 


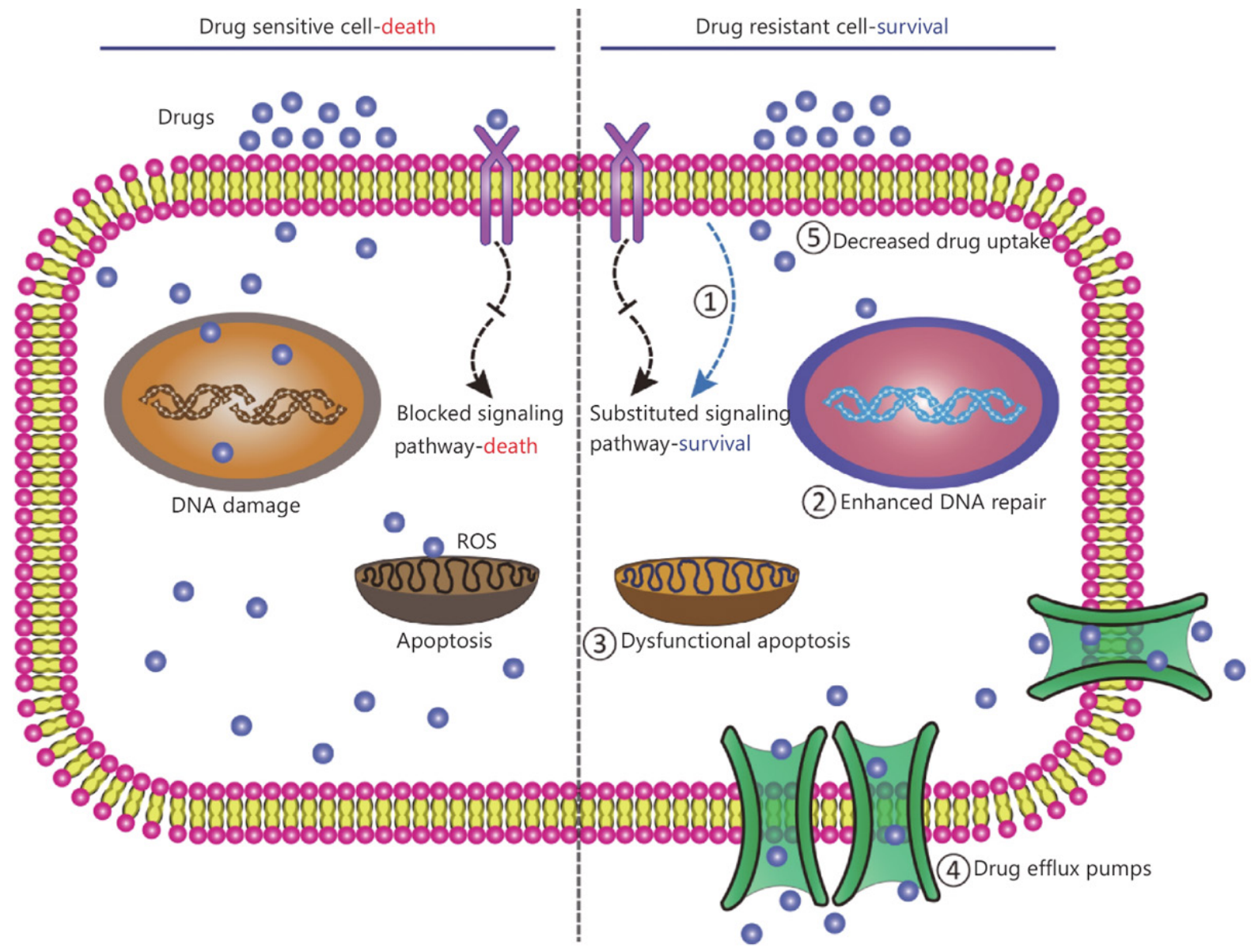

Figure 1. Schematic representation of various cancer drug resistance mechanism ${ }^{[14]}$

retention effect ${ }^{[28]}$. Furthermore, albumin can bind to special receptors overexpressed on cancer cells and enhance nanoparticles binding and internalization. Various tumors overexpress the $60-\mathrm{kDa}$ glycoprotein (gp60) receptor ${ }^{[29]}$, as well as secreted protein acidic and rich in cysteine (SPARC) ${ }^{[30]}$. Albumin can specifically bind to gp60 and SPARC, and, thus, it can actively increase the uptake of the nanoparticles. This particular uptake mechanism allows the albumin-based nanoparticles to bypass the drug efflux mechanisms in tumor cells. It was shown that the binding of paclitaxel, exhibited by nab-paclitaxel, to the endothelium was enhanced by 9.9 folds, and paclitaxel was transported more efficiently by 4.2 folds, compared to Cremophor EL-paclitaxel ${ }^{[27]}$.

Albumin also possesses functional groups, such as amino and carboxylic groups, which can be employed for functionalization of albumin nanoparticles with targeting ligands or active therapeutics ${ }^{[31]}$. Additionally, the stability of albumin nanoparticles allows the systematic delivery of various agents without degradation. For example, albumin nanoparticles successfully delivered siRNA and plasmid-based RNA interference agents $^{[32,33]}$.

\section{FABRICATION TECHNIQUES OF ALBUMIN-BASED NANOCARRIERS EMPLOYED FOR OVERCOMING CANCER DRUG RESISTANCE Desolvation}

Desolvation is the most common technique used for fabrication of albumin nanoparticles. The process of desolvation is brought by a dehydration process of albumin. This dehydration process is induced when 
2. Desolvation

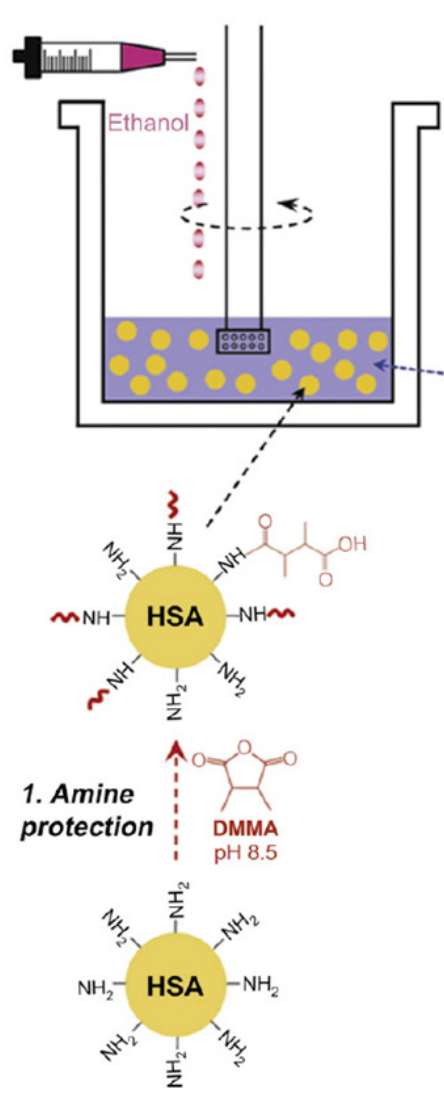

3. Cross-linking

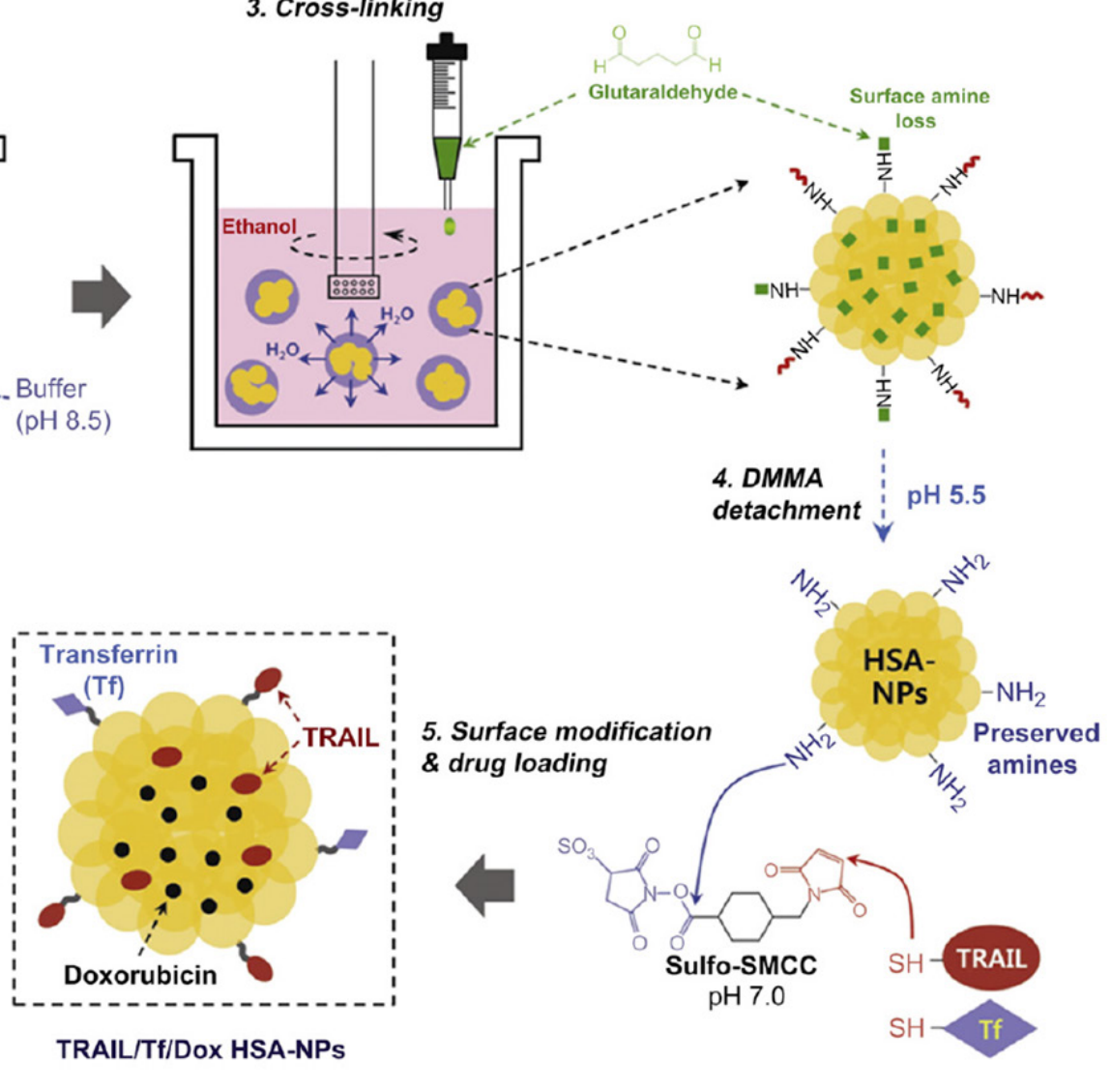

Figure 2. Schematic representation for the preparation of DOX-loaded HSA NPs by desolvation technique, as well as surface functionalization with Transferrin (Tf) and Tumor necrosis factor (TNF)-related apoptosis-inducing ligand (TRAIL) ${ }^{[37]}$. DOX: doxorubicin; HSA: human serum albumin; NPs: nanoparticles

a desolvating agent, for instance, ethanol or acetone, is added to the aqueous solution of albumin. This process induces a conformational change in albumin structure from a stretched to a coiled conformation, and, hence, the formation of nanoparticles. Then, the formed nanoparticles are stabilized by cross-linking agents ${ }^{[34-36]}$. The most commonly employed cross-linking agent is glutaraldehyde. It was shown that the lowest required concentration of glutaraldehyde needed for the stabilization of nanoparticles is $40 \%$, allowing the reaction to proceed for $24 \mathrm{~h}$, ensuring the sufficient cross-linking of albumin amino groups ${ }^{[35]}$. Doxorubicin (DOX)-loaded HSA NPs were prepared by employing the desolvation method. Furthermore, HSA NPs retained their capacity for functionalization with targeting materials as well as active therapeutic agents [Figure 2] ${ }^{[37]}$.

\section{Thermal-induced aggregation}

Thermal mediated unfolding of albumin can be induced by heating albumin solution, for instance at $65{ }^{\circ} \mathrm{C}$. The procedure continues with protein-protein interactions. These interactions are hydrophobic, electrostatic, hydrogen bonding, and disulfide-sulfhydryl interchange interactions ${ }^{[38-40]}$. This method circumvents the potential toxicity, which may be attributed to the addition of organic solvents, in the desolvation method. Cyclopamine (CYC) and doxorubicin hydrochloride (DOX.HCL) were sequentially loaded in BSA NPs, implementing thermal-induced aggregation procedure. DOX.HCL, being water soluble, was mixed with BSA solution before the formation of NPs, while CYC was dissolved in ethanol and then added to the BSA solution. CYC is a hydrophobic drug, and hence the mechanism of CYC loading was shown to be a desolvation process. The mixture was magnetically stirred at $750 \mathrm{rpm}$ in a $65{ }^{\circ} \mathrm{C}$ water bath. Then, the colloidal solution was ultra-filtered to remove any excess buffer or drug ${ }^{[4]}$. 


\section{Self-assembly}

The self-assembly of a protein into nanoparticles can be employed using several techniques. The mainstay in this technique is to increase the hydrophobicity of a water-soluble protein or to impart amphiphilic characteristics to the protein, through conjugation with a hydrophobic material ${ }^{[42]}$. In one study, HSA was activated and conjugated to sulfosuccinimidyl 4-(N-maleimidomethyl)-cyclo-hexane-1-carboxylate (sulfo-SMCC), and then it was conjugated to DOX.HCL. Furthermore, HSA was conjugated with octanal (C8) via reductive amination step, in the presence of sodium cyanoborohydride $\left(\mathrm{NaCNBH}_{3}\right)$. The HSASMCC-DOX-C8 was self-assembled into HSA-DOX nanoparticles by adjusting the $\mathrm{pH}$ to 5.5, due to increased hydrophobicity by conjugated octanal ${ }^{[43]}$. Alternatively, the self-assembly process of albumin can be driven by protein unfolding induced by disulfide bond reduction, using disulfide bond reducing agents, for instance $\beta$-mercaptoethanol. Then, the addition of the hydrophobic drug allows the self-assembly of albumin into nanoparticles, due to non-covalent hydrophobic interactions arising between the drug and albumin $^{[44]}$. Paclitaxel (PTX)-loaded HSA nanoparticles were successfully prepared by implementing the non-covalent protein-drug self-assembly method. First, PEGylated albumin was conjugated to a W peptide (Trp-Lys-Tyr-Met-Val-D-Met), for targeting of formyl peptide receptor overexpressed on triple negative breast cancer (TNBC). Then, glutathione (GSH), a disulfide bond reducing agent, was added to the modified HSA with elevating the temperature to $37^{\circ} \mathrm{C}$, to expose the hydrophobic binding sites of albumin. The formulation was first dialyzed to remove excess GSH, and then an ethanolic solution of PTX was added with the subsequent formation of NPs. This technique offers the advantage of producing redox-responsive nanocarriers, owing to the intermolecular disulfide bridges formed during the self-assembly process ${ }^{[45]}$.

\section{Albumin-bound technology}

Albumin-bound technology (nab-technology) was introduced as an alternative technique for safe and effective systemic drug delivery formulation ${ }^{[46,47]}$. Cremophor-EL was used as a vehicle for the systematic delivery of paclitaxel, which induced anaphylactic reactions to various patients ${ }^{[48]}$. To overcome this limitation, paclitaxel was formulated bound to albumin by nab-technology. Initially, the drug is mixed with the aqueous solution of HSA, and then the mixture is passed through a high-pressure jet to form the drugalbumin nanoparticles ${ }^{[49]}$. These nanoparticles showed a size of $130 \mathrm{~nm}$. The nab-paclitaxel was approved by the FDA, under the trade name of Abraxane ${ }^{\bullet}$, for treatment of metastatic breast cancer. Similarly, for the treatment of drug-resistant pancreatic cancer, gemcitabine (GEM)-loaded albumin was fabricated using the same technique. First, to increase its hydrophobicity, GEM was coupled with myristoyl moiety, to produce GEM-C14. Then, the modified drug was dissolved in chloroform saturated with pure water. The resultant solution was further mixed with HSA solution. The mixture was homogenized at 2000 psi for nine cycles. Chloroform was removed by rotary evaporation under vacuum, syringe filtered and finally lyophilized to obtain powdered nanoparticles ${ }^{[50]}$.

\section{ALBUMIN-BASED NANOCARRIERS TO OVERCOME CANCER DRUG RESISTANCE FOR VARIOUS TYPES OF TUMORS}

Albumin nanocarriers have been prepared, serving as drug delivery systems, to overcome resistance mechanisms developed by various tumors. In this regard, combined anticancer drug delivery, enhanced cellular uptake by gp60- and SPARC-mediated transcytosis, improved drug accumulation, and efficient delivery of labile therapeutics have been investigated [Table 1].

\section{Breast cancer}

Drug efflux is a major pathway for the development of multi-drug resistant breast cancer. The primary mechanism has been found to be the upregulation of the ATP-binding cassette (ABC), which possesses the capacity to pump chemotherapeutic drugs out of the cancer cells ${ }^{[64]}$. A combination treatment with an efflux pump inhibitor would be a promising candidate ${ }^{[13,65]}$. Cyclopamine (CYC), a hedgehog signaling 
Table 1. Albumin-based nanoparticles employed to overcome cancer drug resistance

\begin{tabular}{|c|c|c|c|c|c|c|c|}
\hline Drug & $\begin{array}{c}\text { Particle } \\
\text { size }(\mathbf{n m})\end{array}$ & PDI & Method & Type of cancer & $\begin{array}{l}\text { Type of cancer drug } \\
\text { resistance treated }\end{array}$ & Outcome & Ref. \\
\hline \multicolumn{8}{|c|}{ Bovine serum albumin (BSA) based nanoparticles } \\
\hline $\begin{array}{l}\text { TCS and } \\
\text { ABZ }\end{array}$ & 98 & 0.18 & Self-assembly & Lung cancer & $\begin{array}{l}\text { Phosphorylation of } \\
\text { caspase } 9 \text {, upregulation } \\
\text { of } P \text {-gp, and upregulation } \\
\text { of } \alpha \text {-tubulin }\end{array}$ & $\begin{array}{l}\text { Inhibition of metastasis with an } \\
\text { efficiency }>80 \% \text { against A549/ } \\
\text { T tumor-bearing nude mice }\end{array}$ & {$[51]$} \\
\hline $\begin{array}{l}\text { CCM and } \\
\text { DOX }\end{array}$ & $\begin{array}{l}131 \\
\text { (spherical) }\end{array}$ & $\mathrm{N} / \mathrm{A}$ & $\begin{array}{l}\text { High-pressure } \\
\text { homogenization }\end{array}$ & Lung cancer & $\begin{array}{l}\text { Poor drug uptake, } \\
\text { accumulation, and } \\
\text { decreased response to } \\
\text { monotherapy }\end{array}$ & $\begin{array}{l}\text { Enhanced cytotoxicity with } \\
\text { around } 80 \% \text { cell death }\end{array}$ & {$[52]$} \\
\hline $\begin{array}{l}\text { QT and } \\
\text { DTX }\end{array}$ & 209 & 0.184 & $\begin{array}{l}\text { Antisolvent } \\
\text { precipitation } \\
\text { method }\end{array}$ & Breast cancer & $\begin{array}{l}\text { Increased drug efflux by } \\
\text { P-gp }\end{array}$ & $\begin{array}{l}\text { 4.27- and } 1.87 \text {-fold reduction } \\
\text { in the } \mathrm{IC}_{50} \text { compared to free } \\
\text { DTX and DTX-BSA-NPs, against } \\
\text { MDA-MB- } 231 \text { cells }\end{array}$ & {$[53]$} \\
\hline $\begin{array}{l}\text { CYC and } \\
\text { DOX }\end{array}$ & 151 & 0.206 & $\begin{array}{l}\text { Thermal induced } \\
\text { aggregation }\end{array}$ & Breast cancer & Upregulation of P-gp & $\begin{array}{l}\text { Enhanced accumulation of DOX, } \\
\text { with only } 2 \% \text { survival of DOX- } \\
\text { resistant MDA-MB-231 breast } \\
\text { cancer cells }\end{array}$ & {$[41]$} \\
\hline VE and PTX & 106.9 & 0.172 & $\begin{array}{l}\text { Desolvation- } \\
\text { ultrasonication } \\
\text { method }\end{array}$ & Breast cancer & $\begin{array}{l}\text { Increased drug efflux by } \\
\text { P-gp }\end{array}$ & $\begin{array}{l}\text { Enhanced cytotoxicity, as well as } \\
\text { improve PTX tumor accumulation } \\
\text { against MCF-7/ADR cells }\end{array}$ & [54] \\
\hline $\begin{array}{l}\text { Cur and } \\
\text { DOX }\end{array}$ & 99.94 & 0.193 & $\begin{array}{l}\text { Desolvation } \\
\text { method }\end{array}$ & Breast cancer & Upregulation of P-gp & $\begin{array}{l}\text { A lower cell viability was } \\
\text { exhibited after the treatment with } \\
\text { the Cur-DOX co-loaded albumin } \\
\text { NPs, compared to the Cur loaded } \\
\text { albumin NPs or the DOX loaded } \\
\text { albumin NPs }\end{array}$ & [55] \\
\hline $\begin{array}{l}\text { Ce6 and } \\
\text { DOX }\end{array}$ & $\begin{array}{l}\text { HMSN: } 231 \\
\text { BMHDC: } \\
274\end{array}$ & $\mathrm{~N} / \mathrm{A}$ & $\begin{array}{l}\text { Biomineralization } \\
\text { and Conjugation }\end{array}$ & Cervical cancer & $\begin{array}{l}\text { Hypoxia-associated } \\
\text { photodynamic therapy } \\
\text { resistance }\end{array}$ & $\begin{array}{l}\text { Reduction of Hela cell viability by } \\
\text { more than } 90 \%\end{array}$ & {$[56]$} \\
\hline $\begin{array}{l}\text { disulfuram/ } \\
\text { copper } \\
\text { complex } \\
\text { and Rego }\end{array}$ & 140.4 & 0.185 & $\begin{array}{l}\text { Hydrophobic } \\
\text { drug induced co- } \\
\text { assembly }\end{array}$ & $\begin{array}{l}\text { Colorectal } \\
\text { cancer }\end{array}$ & $\begin{array}{l}\text { Poor drug accumulation } \\
\text { and polarization of TAM } \\
\text { to } \mathrm{M} 2 \text { phenotype }\end{array}$ & $\begin{array}{l}\text { Downregulation of mannose } \\
\text { receptors, and reduction in the } \\
\text { population of } \mathrm{M} 2 \text { macrophages } \\
\text { by up to } 22 \%\end{array}$ & {$[57]$} \\
\hline DOX & 60 & 0.23 & $\begin{array}{l}\text { Desolvation } \\
\text { method }\end{array}$ & $\begin{array}{l}\text { Uterine } \\
\text { sarcoma }\end{array}$ & $\begin{array}{l}\text { P-gp overexpression } \\
\text { resulting in DOX } \\
\text { resistance }\end{array}$ & $\begin{array}{l}\text { DOX-DBSA-NPS, prepared by } \\
\text { DMSO as desolvating agent, } \\
\text { and DOX-SBSA-NPs, prepared } \\
\text { by acetone, as the desolvating } \\
\text { agent, exerted an enhanced } \\
\text { cytotoxicity }\left(\mathrm{IC}_{50}=0.39 \text { and }\right. \\
0.25 \mu \mathrm{mol} / \mathrm{L} \text {, respectively), with } \\
\text { a lower IC } \mathrm{C}_{50} \text { than free DOX }\left(\mathrm{IC}_{50}\right. \\
=2.09 \mu \mathrm{mol} / \mathrm{L})\end{array}$ & {$[58]$} \\
\hline \multicolumn{8}{|c|}{ Human serum albumin (HSA) based nanoparticles } \\
\hline DOX & 496.4 & 0.213 & $\begin{array}{l}\text { Desolvation } \\
\text { method }\end{array}$ & Neuroblastoma & $\begin{array}{l}\text { ABCB1-mediated drug } \\
\text { efflux }\end{array}$ & $\begin{array}{l}\text { Enhanced DOX sensitivity and } \\
\text { anticancer activity against } \\
\text { vincristine adapted UKF-NB- } \\
3^{r} \text { VCR }^{1} \text { cells, but not DOX- } \\
\text { resistant UKF-NB-3'DOX }{ }^{2} \text { cells, } \\
\text { when treated with DOX-loaded } \\
\text { albumin NPs }\end{array}$ & [59] \\
\hline $\begin{array}{l}\text { TRAIL and } \\
\text { DOX }\end{array}$ & 341.6 & $\mathrm{~N} / \mathrm{A}$ & Self-assembly & Lung cancer & $\begin{array}{l}\text { TRAIL or DOX } \\
\text { monotherapy resistance }\end{array}$ & $\begin{array}{l}\text { Enhanced apoptosis against } \\
\text { H226 cells, compared to single } \\
\text { drug-loaded nanoparticles }\end{array}$ & [43] \\
\hline $\begin{array}{l}\text { TRAIL and } \\
\text { DOX }\end{array}$ & 220 & $\mathrm{~N} / \mathrm{A}$ & $\begin{array}{l}\text { Desolvation } \\
\text { method }\end{array}$ & $\begin{array}{l}\text { Colon, breast, } \\
\text { pancreatic } \\
\text { cancer }\end{array}$ & $\begin{array}{l}\text { TRAIL monotherapy } \\
\text { resistance and drug } \\
\text { efflux }\end{array}$ & $\begin{array}{l}99 \% \text { cell-killing against CAPAN-1 } \\
\text { cells }\end{array}$ & {$[37]$} \\
\hline DTX & 248.7 & 0.13 & $\begin{array}{l}\text { Albumin-coated } \\
\text { nanocrystals }\end{array}$ & Ovarian cells & Poor drug uptake & $\begin{array}{l}\text { Enhanced cell uptake by } 2.5 \text { folds } \\
\text { after } 1 \mathrm{~h} \text { and around } 8 \text { folds in } 3 \mathrm{~h} \text {, } \\
\text { via SPARC-mediated mechanism }\end{array}$ & {$[60]$} \\
\hline $\begin{array}{l}\text { DTX and } \\
\text { IR-780 }\end{array}$ & 146.5 & $N / A$ & Self-assembly & Prostate cancer & $\begin{array}{l}\text { Poor efficacy of PTT and } \\
\text { PDT monotherapy }\end{array}$ & $\begin{array}{l}\text { Increased temperature up to } 47.5 \\
{ }^{\circ} \mathrm{C} \text {, with an irreversible tumor } \\
\text { damage }\end{array}$ & {$[61]$} \\
\hline
\end{tabular}




\begin{tabular}{|c|c|c|c|c|c|c|c|}
\hline $\begin{array}{l}\text { Human } \\
\text { survivin- } \\
\text { specific } \\
\text { miRNA } \\
\text { plasmid }\end{array}$ & 220 & 0.04 & $\begin{array}{l}\text { Desolvation } \\
\text { method }\end{array}$ & $\begin{array}{l}\text { Colorectal } \\
\text { cancer }\end{array}$ & $\begin{array}{l}\text { Overexpression of } \\
\text { Survivin }\end{array}$ & $\begin{array}{l}50 \% \text { reduction in survivin } \\
\text { expression, initiation of } \\
\text { apoptosis, and reduction of cell } \\
\text { viability by up to } 60 \% \text { at } 2 \mathrm{~Gy} \text {, } \\
\text { with combined radiotherapy }\end{array}$ & [33] \\
\hline PTX & 118.8 & 0.221 & $\begin{array}{l}\text { Hydrophobic } \\
\text { drug induced co- } \\
\text { assembly }\end{array}$ & TNBC & $\begin{array}{l}\text { Lack of the expression } \\
\text { of HER2, estrogen and } \\
\text { progesterone receptors }\end{array}$ & $\begin{array}{l}\text { Enhanced cellular uptake, and } \\
\text { a lower } \mathrm{IC}_{50}(553.5 \mathrm{ng} / \mathrm{mL}) \\
\text { compared to free PTX }(3612.1 \mathrm{ng} / \\
\mathrm{mL})\end{array}$ & [45] \\
\hline $\begin{array}{l}\text { Cat, Ce6 } \\
\text { and PTX }\end{array}$ & 100 & N/A & $\begin{array}{l}\text { Hydrophobic } \\
\text { drug induced co- } \\
\text { assembly }\end{array}$ & Breast cancer & $\begin{array}{l}\text { Poor intra-tumoral } \\
\text { penetration, tumor } \\
\text { hypoxia }\end{array}$ & $\begin{array}{l}\text { Enhanced PDT, due to generation } \\
\text { of oxygen in situ by the action of } \\
\text { catalase }\end{array}$ & [62] \\
\hline GEM & 150 & N/A & $\begin{array}{l}\text { Albumin-bound } \\
\text { technology }\end{array}$ & $\begin{array}{l}\text { Pancreatic } \\
\text { cancer }\end{array}$ & $\begin{array}{l}\text { low hENT1 expression; } \\
\text { Poor GEM uptake }\end{array}$ & $\begin{array}{l}\text { Reduced tumor volume and } \\
\text { weight compared to free GEM }\end{array}$ & {$[50,63]$} \\
\hline
\end{tabular}

TCS: trichosanthin; ABZ: albendazole; CCM: curcumin; DOX: doxorubicin; QT: quercetin; DTX: docetaxel; CYC: cyclopamine; PTX: paclitaxel; VE: vitamin E; Rego: regorafenib; Cur: curcumin; DOX-DBSA-NPs: doxorubicin loaded doughnut shaped bovine serum albumin nanoparticles; DOX-SBSA-NPs: doxorubicin loaded spherical shaped bovine serum albumin nanoparticles; TRAIL: tumor necrosis factor (TNF)-related apoptosis-inducing ligand; CAPAN-1: human pancreatic ductal adenocarcinoma cell line; SPARC: secreted protein acidic and rich in cysteine; TNBC: triple negative breast cancer; PDT: photodynamic therapy; PTT: photothermal therapy; HER2: human epidermal growth factor receptor 2; Cat: catalase; hENT1: human equilibrative nucleoside transporter 1; GEM: Gemcitabine

pathway inhibitor, was found to regulate the expression of $\mathrm{ABCB} 1$, which is also known as P-glycoprotein $(\mathrm{P}-\mathrm{gp})^{[66]}$. CYC was effectively combined with doxorubicin (DOX) for reversal of drug resistance in breast cancer $^{[67]}$. DOX and CYC were successfully co-loaded in BSA nanoparticles (Drug loading $1.2 \%$ and $9.1 \%$, respectively) using a thermal induced self-assembly process. To its advantage, BSA NPs internalized in tumor cells via gp60- and SPARC-mediated pathways. Notably, BSA-CYC-DOX NPs showed decreased levels of P-gp, as well as enhanced accumulation of DOX, which were consistent with only $2 \%$ survival of DOX-resistant MDA-MB-231 breast cancer cells ${ }^{[4]}$. Similarly, Quercetin (QT), a P-gp inhibitor, was coloaded with Docetaxel (DTX) in BSA NPs, resulting in 4.27- and 1.87 -fold reduction in the $\mathrm{IC}_{50}$ compared to free DTX and DTX-BSA-NPs, against MDA-MB-231 cells. Moreover, these nanoparticles showed the highest fluorescence intensity inside tumor cells, attributed to the effective inhibition of P-gp. DTX-QTBSA-NPs were prepared using anti-solvent precipitation method, with an entrapment efficiency of $75.18 \%$ and $68.09 \%$ for DTX and QT, respectively ${ }^{[53]}$.

Another resistance mechanism towards photodynamic therapy (PDT) was found to be the hypoxic nature of the tumor microenvironment $(\mathrm{TME})^{[68-74]}$. To overcome this hypoxic TME, catalase was used to produce oxygen in-situ, through the specific decomposition of $\mathrm{H}_{2} \mathrm{O}_{2}$ to $\mathrm{O}_{2}{ }^{[75]}$. However, the systematic administration of catalase was limited by the action of blood circulating proteases ${ }^{[76-80]}$. Therefore, catalase was co-loaded with paclitaxel (PTX) using pre-modified HSA-Ce6, to form HSA-Ce6-Cat-PTX nanoparticles. The nanoparticles, which were prepared through the self-assembly procedure of HSA, were formed by the addition of the hydrophobic drug, PTX. The produced nanoparticles $(\sim 100 \mathrm{~nm})$ showed an enhanced PDT, owing to the effective $\mathrm{O}_{2}$ by catalase. Moreover, the catalase maintained about $70 \%$ of its activity after $24 \mathrm{~h}$ incubation of the nanoparticles with protease $\mathrm{K}^{[62]}$.

Triple negative breast cancer (TNBC) lacks the expression of human epidermal growth factor receptor 2 and estrogen and progesterone receptors, which may compromise therapeutic treatment ${ }^{[45]}$. Active targeting was exploited to deliver PTX to TNBC. TNBC overexpresses formyl peptide receptor ${ }^{[81,82]}$, which could be targeted with a W peptide (Trp-Lys-Tyr-Met-Val-D-Met) ${ }^{[83,84]}$. A disulfide bond reduction method ${ }^{[85,86]}$ was employed to induce the self-assembly of Wpep-HSA, following the addition of the hydrophobic drug, PTX. Enhanced intracellular release of Wpep-HSA-PTX NPs was observed, due to redox-responsive behavior, which was attributed to elevated levels of endogenous $\mathrm{GSH}^{[87]}$. The stimuli-responsive drug release pattern was linked to the formation of intermolecular disulfide bonds between HSA NPs ${ }^{[45]}$. Furthermore, these nanoparticles showed an enhanced cellular uptake, and exhibited a lower $\mathrm{IC}_{50}(553.5 \mathrm{ng} / \mathrm{mL})$ compared to free PTX $(3612.1 \mathrm{ng} / \mathrm{mL})$. The favorable anti-proliferative effects, stimuli-responsive drug release, and 
enhanced pharmacokinetic profile of the Wpep-HSA-PTX NPs demonstrated an effective strategy to overcome inadequacies in TNBC treatment. In another investigation, DOX-resistant MCF-7/ADR cells did not respond to TRAIL-HSA NPs therapy. However, the resistant cells were found to respond to the treatment of transferrin-conjugated TRAIL/DOX HSA-NPs. MCF-7/ADR cells possess an efficient efflux mechanism. Therefore, active targeting, to ensure drug internalization and subsequent accumulation, was sought. Transferrin receptors are overexpressed on the MCF-7 cells, and, thus, it was shown that multi-drug resistance (MDR) could be overcome through delivery of TRAIL and DOX, through transferrin-receptor mediated endocytosis ${ }^{[37]}$.

\section{Lung cancer}

Phosphorylation of caspase $9^{[88]}$, upregulation of $\alpha$-tubulin ${ }^{[89]}$, and upregulation of P-gp ${ }^{[90,91]}$ are all resistance mechanisms encountered with metastatic lung cancer. Trichosanthin (TCS) is a ribosome-inactivating $\operatorname{protein}^{[92,93]}$, which re-sensitizes MDR cancer cells by the dephosphorylation of caspase 9. It was shown that TCS could reverse resistance in MDR cancer cells in combination with paclitaxel ${ }^{[88]}$. Moreover, TCS has the potential of preventing the polymerization of tubulins. In an attempt to synergistically overcome MDR lung cancer, albumin-coated silver nanoparticles were synthesized for the co-delivery of albendazole and the recombinant fusion (rTL) protein of trichosanthin with low molecular weight protamine (LWMP). The cationic rTL was self-assembled on the negatively charged albendazole-loaded BSA/Ag NPs via electrostatic interactions. Exploiting SPARC-mediated cellular internalization, these nanoparticles resulted in dephosphorylation of caspase 9, downregulation of P-gp, and downregulation of $\alpha$-tubulin. Additionally, the mitochondrial membrane potential was reverted to low voltage-mitochondrion, indicating the collapse of the mitochondrial membrane and subsequent initiation of apoptosis [Figure 3] ${ }^{[94]}$. Finally, TCScontaining nanoparticles inhibited metastasis with an efficiency $>80 \%$ against A549/T tumor-bearing nude mice, confirming the efficiency of TCS as a treatment in resistant and metastatic cancers ${ }^{[51]}$.

Tumor necrosis factor (TNF)-related apoptosis-inducing ligand (TRAIL), which binds to the overexpressed death receptor 4 and 5, exhibited limited efficacy as a monotherapy in resistant cancer cells ${ }^{[95-98]}$. However, when combined with chemotherapeutic drugs, TRAIL was found to be an effective treatment ${ }^{[99-101]}$. To overcome resistance to TRAIL, DOX and TRAIL were combined to fabricate a single nanomedicinebased system. DOX was conjugated to HSA and self-assembled by virtue of increased hydrophobicity, secondary to conjugation of octanoic acid to HSA. TRAIL was then added to coat the DOX-loaded HSA NPs through sonication in an ice bath. The inhalable nanoparticles were retained in the lung for three days, exerting synergistic apoptotic activity against H226 cells, compared to DOX-loaded HSA NPs or TRAILloaded HSA nanoparticles ${ }^{[43]}$. An injectable formulation of Curcumin (CCM) and DOX-co-loaded BSA NPs was fabricated by high pressure homogenization/nab-technology for the treatment of metastatic lung cancer. The synergistic combination (Combination index: 0.6069) showed an enhanced cytotoxicity with around $80 \%$ cell death. These nanoparticles exploited the ability of BSA to target gp60, which allowed their internalization into the cancer cells ${ }^{[52]}$.

\section{Pancreatic cancer}

Pancreatic ductal adenocarcinoma (PDAC) is an aggressive type of cancer. The first line agent for treatment of PDAC is gemcitabine (GEM $)^{[102]}$. However, GEM, a hydrophilic nucleoside analog, utilizes human nucleoside transporters $(\mathrm{hNT})$ for drug transport into cancer cells ${ }^{[103]}$. One main factor for PDAC chemoresistance is the low expression of one of hNTs, namely the human equilibrative nucleoside transporter $(\mathrm{hENT})^{[104,105]}$. A promising strategy was investigated to increase the lipophilicity of GEM, conjugating a myristoyl moiety (C14) with the 4-amino group of GEM (GEM-C14). GEM-C14 was loaded in HSA NPs produced by albumin-bound technology (nab-technology ${ }^{[50]}$. Thus, GEM-HSA NPs would overcome the low expression of hENT, utilizing the active targeting properties of HSA (gp60 and SPARC targeting) receptor mediated endocytosis. GEM-HSA NPs showed marked tumor growth inhibition (more reduced tumor volume and weight) compared to free GEM and control group ${ }^{[63]}$. 


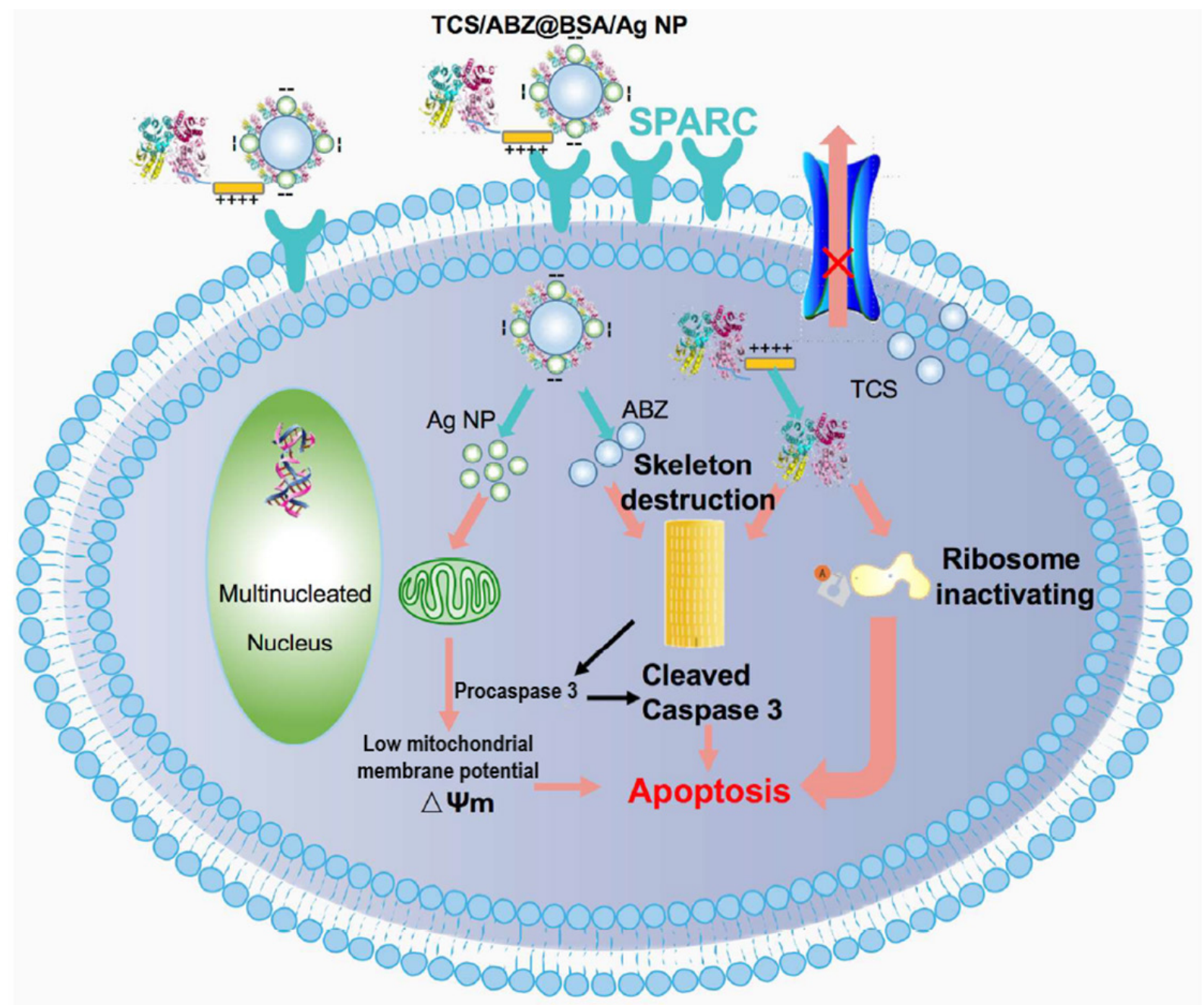

Figure 3. Schematic representation of TCS/ABZ-BSA/Ag NPs internalization utilizing SPARC-mediated endocytosis, as well as antitumor mechanisms against $A 549 / T$ cells ${ }^{[51]}$

As previously demonstrated, TRAIL is an effective treatment only in combination with other anticancer agents, for instance the chemotherapeutic agent DOX. DOX-loaded HSA NPs, prepared via desolvation method and cross-linked with glutaraldehyde, were surface-decorated with TRAIL and transferrin, by virtue of the amine groups of HSA NPs. Transferrin allowed the NPs to be actively internalized in CAPAN-1 (pancreatic cell line model, less sensitive to necrosis and apoptosis), via receptor mediated endocytosis. Furthermore, the combination of TRAIL and DOX exerted more apoptotic activity (> 80\% cell-killing), especially due to the action of TRAIL, at lower doses of TRAIL and DOX, in vivo compared to TRAIL monotherapy. However, on administration of TRAIL/Tf/DOX HSA NPs, 99\% CAPAN-1 cell-killing was demonstrated by FACS analysis ${ }^{[37]}$.

Immune evasion is one of the resistance mechanisms developed by various tumors ${ }^{[106]}$. One way to avoid immune recognition by cancer cells is the polarization of tumor-associated macrophages (TAM) from the M1 phenotype to the immunosuppressive, M2 phenotype. To overcome this mechanism of resistance in PDAC, a nano-formulation of paclitaxel-loaded albumin was prepared by albumin-bound technology (nab-paclitaxel). Targeting gp60 and SPARC, the internalization of nab-paclitaxel into TAM induced the activation of M1 Phenotypes ${ }^{[107]}$. 


\section{Colorectal cancer}

Resistance of colorectal cancer cells against radiotherapy was assumed to be mediated by some molecular targets. One example is survivin, which is an inhibitor of apoptosis ${ }^{[108]}$. Knockdown of survivin via plasmid-mediated RNA interference is a promising strategy ${ }^{[109,110]}$. However, plasmids may be unstable, due to degradation by nucleases. To overcome this challenge, it was found that the loading of a plasmid in HSA NPs, prepared by a desolvation technique and stabilized via cross-linking with glutaraldehyde, is a successful approach. The plasmid loaded in HSA NPs was stable against DNase 1, compared to free plasmid. Moreover, at a concentration corresponding to $300 \mu \mathrm{g}$ of the plasmid, 50\% downregulation of survivin expression was observed. The reduced expression of survivin resulted in the initiation of apoptosis with reduced cell viability, which was further enhanced with combined radiotherapy for up to $60 \%$ reduced cell viability at $2 \mathrm{~Gy}$. A greater reduction in cell viability was observed with increasing doses of radiotherapy $(\text { at } 8 \mathrm{~Gy})^{[33]}$.

The tumor microenvironment may be associated with chemoresistance, as well as tumor progression and angiogenesis. It was found that the polarization of tumor-associated macrophages (TAM) to the M2 phenotype may induce chemotherapeutic drug resistance ${ }^{[11]}$. Interestingly, mannose receptors (MR) were found to be overexpressed on M2 macrophages, which can be targeted with mannose-conjugated nanoparticles, and subsequent internalization of the nanocarriers into the cell via receptor mediated endocytosis $^{\left[1{ }^{1115]}\right.}$. In this regard, mannose- functionalized BSA (Man-BSA) NPs were synthesized, coencapsulating disulfuram/copper complex (DSF/Cu), as well as regorafenib (Rego). The nanoparticles were prepared by hydrophobic mediated self-assembly, induced by the addition of the hydrophobic drugs, secondary to $\mathrm{NabH}_{4}$ /urea protein-unfolding. Man-BSA NPs exhibited three-fold higher cellular uptake than BSA NPs, due to the overexpression of MR receptors on the drug-resistant colon cancer cell line: HCT8/ADR cells. The combinatorial effect of the drug-loaded BSA NPs resulted in an effective therapeutic outcome through a number of pathways: (1) elevated reactive oxygen species (ROS) generation; (2) antiangiogenic activity, mediated by regorafenib; (3) induction of autophagy and apoptosis pathways; and, more importantly; and (4) the reversion of M2 macrophages to M1 phenotype, which was mainly by regorafenib and further enhanced by the dual drug-loaded BSA NPs and was evident by downregulation of mannose receptors. Moreover, the Man-BSA NPs showed the strongest reduction in the population of M2 macrophages, up to $22 \%$. These results highlight the significance of targeting the tumor microenvironment, which can enhance the treatment outcomes in MDR cancers ${ }^{[57]}$.

\section{Prostate cancer}

Castration-resistant prostate cancer is presented with continuous rise in the serum levels of the prostatespecific antigen (PSA) or development of new metastases ${ }^{[16]}$. Combined treatment with photothermal and photodynamic therapy plus chemotherapy offers advantages over monotherapy ${ }^{[117,118]}$. However, limited by poor drug pharmacokinetics and reduced tumor accumulation, the clinical application of these agents is severely compromised. In an attempt to overcome drug resistance and improve the therapeutic outcome of these agents, a nanomedicine-based system was developed to encapsulate both docetaxel (DTX) and a near-infrared dye, IR-780. The hydrophobic drugs triggered the self-assembly of HSA into nanoparticles, following $\beta$-mercaptoethanol-mediated unfolding of HSA. The dual drug loaded HSA NPs were taken up by tumor cells and exhibited an increased temperature up to $47.5{ }^{\circ} \mathrm{C}$, which was enough for irreversible tumor damage. Additionally, these nanoparticles allowed an efficient generation of ROS. Subsequently, HSA-IR780-DTX NPs with NIR laser irradiation showed marked reduction in cell viability at 1 and $1.5 \mu \mathrm{g} / \mathrm{mL}$ concentrations, compared to monotherapy, which was mainly attributed to IR-780 ${ }^{[61]}$.

\section{Cervical cancer}

To overcome tumor hypoxia and enhance photodynamic (PDT) therapy in cervical carcinoma, DOX-and Ce6-loaded mesoporous silica nanoparticles were synthesized and further conjugated to $\mathrm{BSA}^{-} \mathrm{MnO} \mathrm{NPs}_{2}$ 
through a disulfide linkage to produce BSA-MnO2-HMSNs-DOX-Ce6 (BMHDC) nanoparticles. BSA$\mathrm{MnO}_{2} \mathrm{NPs}$ were prepared by a biomineralization strategy ${ }^{[19]}$. These gated nanoparticles showed a stimuliresponsive behavior and an on-demand cargo release. $\mathrm{BSA}-\mathrm{MnO}_{2}$ acted not only to control drug release in response to $\mathrm{pH}$ (5.5 and 7.4) and GSH of the TME, but also generated oxygen utilizing endogenous $\mathrm{H}_{2} \mathrm{O}_{2}$, relieving tumor hypoxia to enhance PDT treatment. Moreover, intracellular delivery of BMHDC nanoparticles resulted in a 2.1 -fold increase in intracellular DOX, compared to free DOX, as well as enhanced oxygen production. Interestingly, only $62 \%$ of the Hela and L929 cells died when treated with HMSNs-DOX-Ce6 only. Cell viability was further reduced, where more than $90 \%$ cells died, when the cells were treated with BMHDC nanoparticles and irradiated with NIR laser, suggesting the role of BSA- $\mathrm{MnO}_{2}$ in enhancing PDT treatment ${ }^{[56]}$.

\section{Ovarian cancer}

Docetaxel (DTX) is an alternative treatment for ovarian cancer with fewer side effects than paclitaxel (PTX). However, drug-resistance can develop as a consequence of drug efflux, and thereby reduce drug accumulation at the tumor site. Albumin is exploited to facilitate the intracellular delivery of DTX to P-gp expressing NCI/ADR-RES cells. Initially, DTX was formulated as nanocrystals stabilized with Pluronic F127, then incubated with HSA water solution, to produce the DTX-loaded HSA NPs. The DTX-HSA NPs were more taken up ( 2.5 folds after $1 \mathrm{~h}$ and $\sim 8$ folds in $3 \mathrm{~h}$ ) by the cancer cells via SPARC-mediated mechanism, bypassing drug efflux by P-gp. This resulted in an improved cytotoxic effect of DTX-HSA NPs over $4 \mathrm{~h}$ period compared to free DTX, showing extended release behavior intracellularly ${ }^{[60]}$.

\section{Uterine sarcoma}

Uterine sarcoma is a type of cancer which develops at the muscular sites of the uterus. MES-SA/DX-5 is a 100 -fold DOX-resistant cell line model of uterine sarcoma, which overexpresses P-gp ${ }^{[120]}$. DOXloaded BSA NPs were prepared via desolvation technique. DMSO was employed to produce doughnutshaped NPs (DBSA-NPs) and compared to spherical-shaped nanoparticles (SBSA-NPs). No difference was observed between MDR cell line and the non-resistant cell line, MOLT-4. Moreover, the cytotoxicity of both formulations, DOX-DBSA-NPs and DOX-SBSA-NPs, showed comparable results $\left(\mathrm{IC}_{50}=0.39\right.$ and $0.25 \mu \mathrm{mol} / \mathrm{L}$, respectively), which were lower than free $\operatorname{DOX}\left(\mathrm{IC}_{50}=2.09 \mu \mathrm{mol} / \mathrm{L}\right)$, indicating inhibition of the proliferation of MDR cells and the bypassing of P-gp drug efflux ${ }^{[58]}$.

\section{FUTURE PERSPECTIVES AND CHALLENGES}

Nanotechnology-based drug delivery is a promising strategy to overcome cancer drug resistance ${ }^{[14]}$. Albumin nanocarriers are attracting considerable attention, provided by their favorable characteristics compared to other nanomaterials. However, some drawbacks may hinder their application. For instance, the application of bovine serum albumin may result in immunogenic reactions, being from animal source $^{[121]}$. Moreover, organic solvents, which are implemented in the fabrication of albumin nanoparticles, may compromise their safety. For example, the toxicity profiles of glutaraldehyde ${ }^{[122]}$, employed for crosslinking of albumin nanoparticles, or $\beta$-mercaptoethanol ${ }^{[123]}$, used to induce disulfide bond reduction for subsequent self-assembly, may hinder the application of the produced nano-formulations ${ }^{[44]}$. On the other hand, the stability of albumin may be compromised by some nano-fabrication conditions. For instance, it was shown that the stability of albumin is compromised on the application of high-pressure homogenization technique (nab-technology) ${ }^{[124]}$.

Tuned drug release could be a potential strategy to overcome cancer drug resistance. The single loaded curcumin (Cur) albumin NPs and single DOX albumin NPs were administered sequentially, as well as simultaneously, to the MCF-7 resistant breast cancer cells. Although the simultaneous administration of both albumin NPs exhibited an increased accumulation of DOX and an enhanced cytotoxicity compared to the sequential administration, a lower Cur accumulation was demonstrated. This led to the limited 


\section{Sequential co-administration}

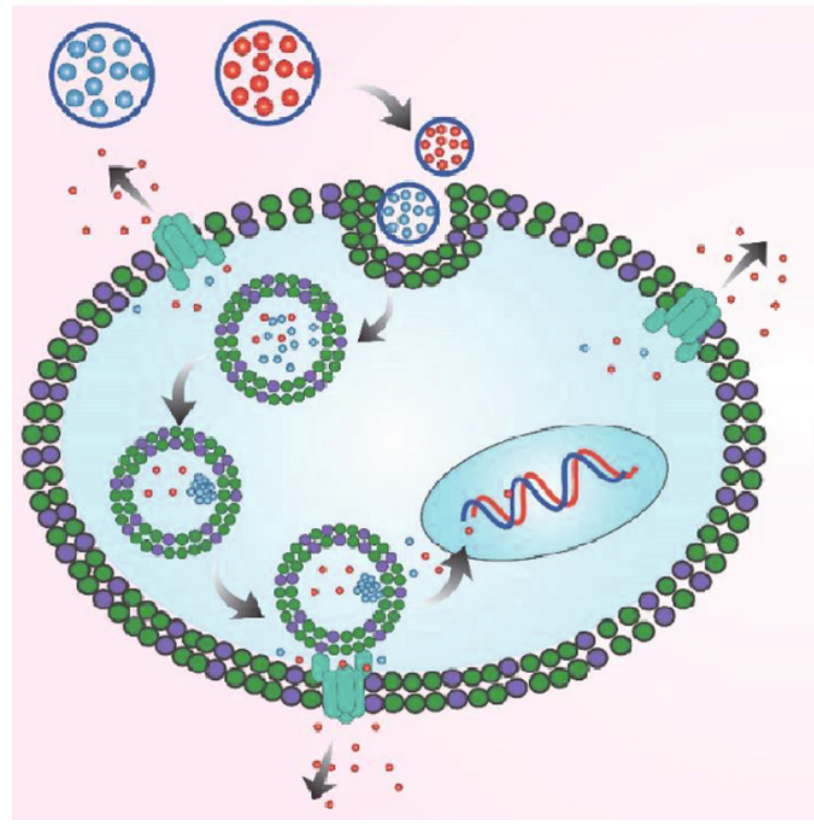

Simultaneous co-administration

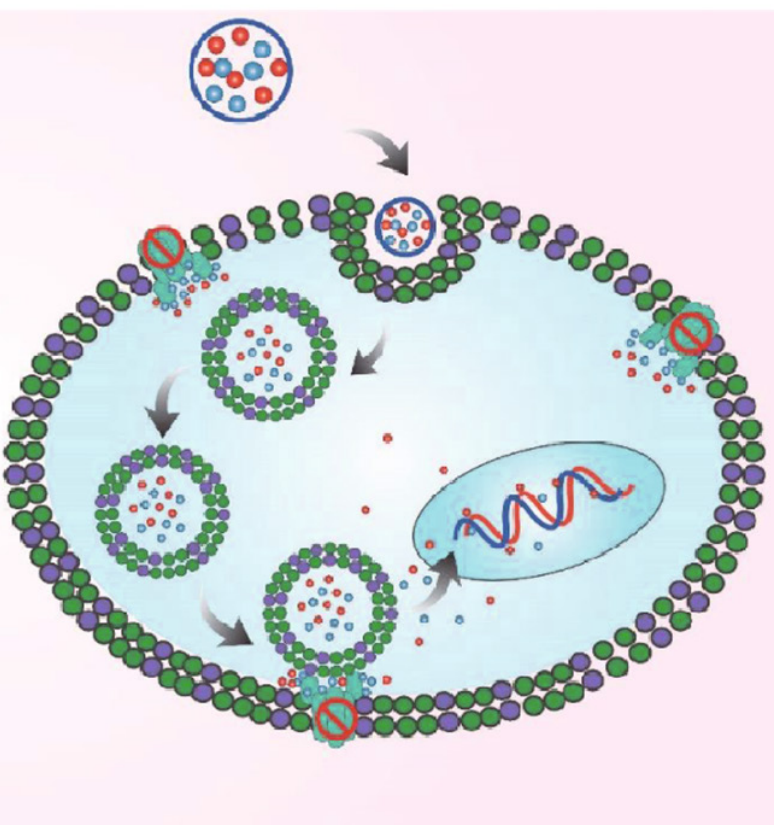

Figure 4. A schematic presentation showing the effective inhibition drug efflux inhibition by tuned drug administration and release mechanisms, mediated by Cur and DOX co-loaded albumin NPs ${ }^{[55]}$. Cur: curcumin; DOX: Doxorubicin; NPs: nanoparticles

P-gp inhibition by Cur. The challenging aspect was the internalization and release manner of Cur in lysosomes. The low $\mathrm{pH}$ exhibited by the lysosome caused Cur to aggregate, a phenomenon known as lysosomotropism ${ }^{[125]}$, which compromised the efficacy of Cur. On the contrary, both DOX and Cur co-loaded albumin NPs, showing a concomitant drug release, displayed a more efficient cell killing. Interestingly, the release of DOX exhibited a buffering capacity, elevating the lysosomal $\mathrm{pH}$, which caused lysosomal drug release and kept the Cur in a dispersed form. Once both were released in the cytosol, Cur, in its dispersed form, efficiently inhibited P-gp, which prevented the efflux of DOX from the cancer cells [Figure 4$]^{[55]}$.

Despite the significance of $\mathrm{ABCB} 1$ transporter, as cancer drug resistance target, it was shown that $\mathrm{ABCB} 1$ inhibitors, as well as DOX-loaded albumin nanocarriers, failed to achieve therapeutic goal in vitro against drug-resistant neuroblastoma cells. It was shown that the DOX-resistant UKF-NB- $3^{\mathrm{r}} \mathrm{DOX}^{20}$ cells were not re-sensitized by either an $\mathrm{ABCB} 1$ inhibitor, zosuquidar, or the DOX-loaded albumin nanoparticles. On the contrary, vincristine adapted UKF-NB- $3^{\mathrm{r}} \mathrm{VCR}^{1}$ cells, which overexpress $\mathrm{ABCB} 1$ transporter, were sensitive to the DOX-loaded albumin nanoparticles. It was conferred that DOX-resistant UKF-NB- $3^{\mathrm{r}} \mathrm{DOX}^{20}$ cells possess multiple resistance mechanisms, which were not sufficiently targeted with an efflux transporter inhibitor or albumin nanocarriers. The internalization of albumin nanoparticles, which was efficient in the treatment of the UKF-NB- ${ }^{\mathrm{r}} \mathrm{VCR}^{1}$ cells, is mediated by binding of albumin to the albumin receptors overexpressed on tumor cells. However, variations in drug loading mechanisms as well as the kinetics of drug release may influence the therapeutic efficiency ${ }^{[126,127]}$. The findings of this study provided primary evidence for the importance of understanding personalized therapy against drug-resistant cancer, provided by more comprehensive insights about cancer drug resistance mechanisms ${ }^{[59]}$. For instance, elucidating the mechanism of resistance by certain biomarkers may enhance albumin-based drug delivery, based on the specific characteristics of the tumor. Moreover, targeting multiple cancer drug resistance mechanisms, through combined drug use, may represent an alternative strategy. In addition, active targeting, by exploiting the functionalization properties of albumin, may pave the way for more efficient drug delivery 
for specific tumors, hence overcoming drug resistance. Nano-theranostics, based on albumin nanoparticles, are a promising approach that allow personalized treatment utilizing imaging and therapeutic modalities. Finally, more studies are required on other drug-resistant tumors, investigating the possibility of targeting multiple resistance mechanisms, tumor imaging, and, more importantly, site-specific drug delivery.

\section{CONCLUSION}

Albumin nanocarriers have shown advantageous characteristics, including biodegradability, biocompatibility, and favorable toxicological profiles. Albumin was able to target overexpressed gp-60 and SPARC receptors, allowing an enhanced drug uptake and bypassing drug efflux mechanisms. Moreover, albumin nanocarriers improved the stability of sensitive therapeutic cargos, such as nucleic acids. Albumin nanocarriers demonstrated the capacity for functionalization with targeting materials and active therapeutics. Furthermore, stimuli-responsive drug release can be implemented utilizing albumin nanoparticles. Collectively, nanomedicine-based albumin drug delivery is a promising strategy to overcome cancer drug resistance.

\section{DECLARATIONS}

\section{Authors' contributions}

Made substantial contributions to the conception and design: Hassanin I, Elzoghby A

Have the work and substantively revised it: Hassanin I

\section{Availability of data and materials}

Not applicable.

\section{Financial support and sponsorship}

None.

\section{Conflicts of interest}

Both authors declared that there are no conflicts of interest.

\section{Ethical approval and consent to participate}

Not applicable.

\section{Consent for publication}

Not applicable.

\section{Copyright}

(c) The Author(s) 2020.

\section{REFERENCES}

1. Falzone L, Salomone S, Libra M. Evolution of cancer pharmacological treatments at the turn of the third millennium. Front Pharmacol 2018;9:1300.

2. Schirrmacher V. From chemotherapy to biological therapy: a review of novel concepts to reduce the side effects of systemic cancer treatment (Review). Int J Oncol 2019;54:407-19.

3. Mansoori B, Mohammadi A, Davudian S, et al. The different mechanisms of cancer drug resistance: a brief review. Adv Pharm Bull 2017;7:339-48.

4. Wang X, Zhang H, Chen X. Drug resistance and combating drug resistance in cancer. Cancer Drug Resist 2019;2:141-60.

5. Nounou MI, ElAmrawy F, Ahmed N, et al. Breast cancer: conventional diagnosis and treatment modalities and recent patents and technologies. Breast Cancer (Auckl) 2015;9:17-34.

6. Housman G, Byler S, Heerboth S, et al. Drug resistance in cancer: an overview. Cancers (Basel) 2014;6:1769-92.

7. Schneider B, Münkel S, Krippner-Heidenreich A, et al. Potent antitumoral activity of TRAIL through generation of tumor-targeted single- 
chain fusion proteins. Cell Death Dis 2010;1:e68.

8. Szakács G, Paterson JK, Ludwig JA, et al. Targeting multidrug resistance in cancer. Na rev Drug discov 2006;5:219-34.

9. Allen TM. Ligand-targeted therapeutics in anticancer therapy. Nat Rev Cancer 2002;2:750-63.

10. Lee ES, Oh KT, Kim D, et al. Tumor pH-responsive flower-like micelles of poly(L-lactic acid)-b-poly(ethylene glycol)-b-poly(Lhistidine). J Control Release 2007;123:19-26.

11. Kim D, Gao ZG, Lee ES, et al. In vivo evaluation of doxorubicin-loaded polymeric micelles targeting folate receptors and early endosomal pH in drug-resistant ovarian cancer. Mol Pharm 2009;6:1353-62.

12. Palmer AC, Sorger PK. Combination cancer therapy can confer benefit via patient-to-patient variability without drug additivity or synergy. Cell 2017;171:1678-91.e13.

13. Leary M, Heerboth S, Lapinska K, et al. Sensitization of drug resistant cancer cells: a matter of combination therapy. Cancers (Basel) 2018;10:483.

14. Zhang M, Liu E, Cui Y, et al. Nanotechnology-based combination therapy for overcoming multidrug-resistant cancer. Cancer Biol Med 2017;14:212-27.

15. Da Silva CG, Peters GJ, Ossendorp F, et al. The potential of multi-compound nanoparticles to bypass drug resistance in cancer. Cancer Chemother Pharmacol 2017;80:881-94.

16. Yuan Y, Cai T, Xia X, et al. Nanoparticle delivery of anticancer drugs overcomes multidrug resistance in breast cancer. Drug Delivery 2016;23:3350-7.

17. Verma D, Gulati N, Kaul S, et al. Protein based nanostructures for drug delivery. J Pharm (Cairo) 2018;2018:9285854.

18. Mao SJ, Hou SX, He R, et al. Uptake of albumin nanoparticle surface modified with glycyrrhizin by primary cultured rat hepatocytes. World J Gastroenterol 2005;11:3075-9.

19. Kremer P, Wunder A, Sinn H, et al. Laser-induced fluorescence detection of malignant gliomas using fluorescein-labeled serum albumin: experimental and preliminary clinical results. Neurological Research 2000;22:481-9.

20. Parodi A, Miao J, Soond SM, et al. Albumin nanovectors in cancer therapy and imaging. Biomolecules 2019;9:218.

21. Maeda H, Wu J, Sawa T, et al. Tumor vascular permeability and the EPR effect in macromolecular therapeutics: a review. $J$ Control Release 2000;65:271-84.

22. Rempel SA, Ge S, Gutiérrez JA. SPARC: a potential diagnostic marker of invasive meningiomas. Clin Cancer Res 1999;5:237-41.

23. Hirose M, Tachibana A, Tanabe T. Recombinant human serum albumin hydrogel as a novel drug delivery vehicle. Mat Sci Eng C 2010;30:664-9.

24. Elzoghby AO, Samy WM, Elgindy NA. Albumin-based nanoparticles as potential controlled release drug delivery systems. $J$ Control Release 2012;157:168-82.

25. Hu YJ, Liu Y, Sun TQ, et al. Binding of anti-inflammatory drug cromolyn sodium to bovine serum albumin. Int J Biol Macromol 2006;39:280-5.

26. Tantra R, Tompkins J, Quincey P. Characterisation of the de-agglomeration effects of bovine serum albumin on nanoparticles in aqueous suspension. Colloids Surf B Biointerfaces 2010;75:275-81.

27. Kratz F. A clinical update of using albumin as a drug vehicle - a commentary. J Control Release 2014;190:331-6.

28. Elzoghby AO, Elgohary MM, Kamel NM. Implications of protein- and Peptide-based nanoparticles as potential vehicles for anticancer drugs. Adv Protein Chem Struct Biol 2015;98:169-221.

29. Lee ES, Youn YS. Albumin-based potential drugs: focus on half-life extension and nanoparticle preparation. $J$ Pharm Investig 2016;46:305-15.

30. Vaz J, Ansari D, Sasor A, et al. SPARC: a potential prognostic and therapeutic target in pancreatic cancer. Pancreas 2015;44:1024-35.

31. An FF, Zhang XH. Strategies for preparing albumin-based nanoparticles for multifunctional bioimaging and drug delivery. Theranostics 2017;7:3667-89.

32. Son S, Song S, Lee SJ, et al. Self-crosslinked human serum albumin nanocarriers for systemic delivery of polymerized siRNA to tumors. Biomaterials 2013;34:9475-85.

33. Gaca S, Reichert S, Rodel C, et al. Survivin-miRNA-loaded nanoparticles as auxiliary tools for radiation therapy: preparation, characterisation, drug release, cytotoxicity and therapeutic effect on colorectal cancer cells. J Microencapsul 2012;29:685-94.

34. Langer K, Balthasar S, Vogel V, et al. Optimization of the preparation process for human serum albumin (HSA) nanoparticles. Int $J$ Pharmaceut 2003;257:169-80.

35. Weber C, Coester C, Kreuter J, et al. Desolvation process and surface characterisation of protein nanoparticles. Int J Pharm 2000;194:91102 .

36. Gong J, Huo M, Zhou J, et al. Synthesis, characterization, drug-loading capacity and safety of novel octyl modified serum albumin micelles. Int J Pharm 2009;376:161-8.

37. Bae S, Ma K, Kim TH, et al. Doxorubicin-loaded human serum albumin nanoparticles surface-modified with TNF-related apoptosisinducing ligand and transferrin for targeting multiple tumor types. Biomaterials 2012;33:1536-46.

38. Yu S, Yao P, Jiang M, et al. Nanogels prepared by self-assembly of oppositely charged globular proteins. Biopolymers 2006;83:148-58.

39. Qi J, Yao P, He F, et al. Nanoparticles with dextran/chitosan shell and BSA/chitosan core--doxorubicin loading and delivery. Int J Pharm 2010;393:176-84.

40. Bronich TK, Keifer PA, Shlyakhtenko LS, et al. Polymer micelle with cross-linked ionic core. J Am Chem Soc 2005;127:8236-7.

41. Lu YL, Ma YB, Feng C, et al. Co-delivery of cyclopamine and doxorubicin mediated by bovine serum albumin nanoparticles reverses doxorubicin resistance in breast cancer by down-regulating P-glycoprotein Expression. $J$ Cancer 2019;10:2357-68. 
42. Xu R, Fisher M, Juliano RL. Targeted albumin-based nanoparticles for delivery of amphipathic drugs. Bioconjugate Chem 2011;22:870-8.

43. Choi SH, Byeon HJ, Choi JS, et al. Inhalable self-assembled albumin nanoparticles for treating drug-resistant lung cancer. $J$ Controll Release 2015;197:199-207.

44. Hassanin IA, Elzoghby AO. Self-assembled non-covalent protein-drug nanoparticles: an emerging delivery platform for anti-cancer drugs. Expert Opin Drug Del 2020;4:1-22.

45. Liu L, Bi Y, Zhou M, et al. Biomimetic human serum albumin nanoparticle for efficiently targeting therapy to metastatic breast cancers. ACS Appl Mater Interfaces 2017;9:7424-35.

46. Fu Q, Sun J, Zhang W, et al. Nanoparticle albumin-bound (NAB) technology is a promising method for anti-cancer drug delivery. Recent Pat Anticancer Drug Discov 2009;4:262-72.

47. Cortes J, Saura C. Nanoparticle albumin-bound (nab ${ }^{\mathrm{TM}}$ )-paclitaxel: improving efficacy and tolerability by targeted drug delivery in metastatic breast cancer. Eur J Cancer Suppl 2010;8:1-10.

48. Gelderblom H, Verweij J, Nooter K, et al. Cremophor EL: the drawbacks and advantages of vehicle selection for drug formulation. Eur $J$ Cancer Suppl 2001;37:1590-8.

49. Desai N, Trieu V, Yao Z, et al. Increased antitumor activity, intratumor paclitaxel concentrations, and endothelial cell transport of cremophor-free, albumin-bound paclitaxel, ABI-007, compared with cremophor-based paclitaxel. Clin Cancer Res 2006;12:1317-24.

50. Yu X, Di Y, Xie C, et al. An in vitro and in vivo study of gemcitabine-loaded albumin nanoparticles in a pancreatic cancer cell line. Int $J$ Nanomed 2015;10:6825-34.

51. Tang Y, Liang J, Wu A, et al. Co-delivery of trichosanthin and albendazole by nano-self-assembly for overcoming tumor multidrugresistance and metastasis. ACS Appl Mater Interfaces 2017;9:26648-64.

52. Kim B, Seo B, Park S, et al. Albumin nanoparticles with synergistic antitumor efficacy against metastatic lung cancers. Colloids Surf B Biointerfaces 2017; 158:157-66.

53. Desale JP, Swami R, Kushwah V, et al. Chemosensitizer and docetaxel-loaded albumin nanoparticle: overcoming drug resistance and improving therapeutic efficacy. Nanomedicine (London) 2018;13:2759-76.

54. Tang B, Qian Y, Gou Y, et al. VE-albumin core-shell nanoparticles for paclitaxel delivery to treat MDR breast cancer. Molecules 2018;23:2760.

55. Motevalli SM, Eltahan AS, Liu L, et al. Co-encapsulation of curcumin and doxorubicin in albumin nanoparticles blocks the adaptive treatment tolerance of cancer cells. Biophys Rep 2019;5:19-30.

56. Fang J, Wang Q, Yang G, et al. Albumin-MnO2 gated hollow mesoporous silica nanosystem for modulating tumor hypoxia and synergetic therapy of cervical carcinoma. Colloids Surf B Biointerfaces 2019;179:250-9.

57. Zhao P, Yin W, Wu A, et al. Dual-targeting to cancer cells and M2 macrophages via biomimetic delivery of mannosylated albumin nanoparticles for drug-resistant cancer therapy. Adv Funct Mater 2017;27.

58. Kayani Z, Firuzi O, Bordbar AK. Doughnut-shaped bovine serum albumin nanoparticles loaded with doxorubicin for overcoming multidrug-resistant in cancer cells. Int J Biol Macromol 2018;107:1835-43.

59. Onafuye H, Pieper S, Mulac D, et al. Doxorubicin-loaded human serum albumin nanoparticles overcome transporter-mediated drug resistance in drug-adapted cancer cells. Beilstein J Nanotechnol 2019;10:1707-15.

60. Gad SF, Park J, Park JE, et al. Enhancing docetaxel delivery to multidrug-resistant cancer cells with albumin-coated nanocrystals. Mol Pharm 2018; doi: 10.1021/acs.molpharmaceut.7b00783.

61. Lian $\mathrm{H}, \mathrm{Wu}$ J, Hu Y, et al. Self-assembled albumin nanoparticles for combination therapy in prostate cancer. Int J Nanomedicine 2017;12:7777-87.

62. Chen Q, Chen J, Liang C, et al. Drug-induced co-assembly of albumin/catalase as smart nano-theranostics for deep intra-tumoral penetration, hypoxia relieve, and synergistic combination therapy. J Control Release 2017;263:79-89.

63. Guo Z, Wang F, Di Y, et al. Antitumor effect of gemcitabine-loaded albumin nanoparticle on gemcitabine-resistant pancreatic cancer induced by low hENT1 expression. Int J Nanomedicine 2018;13:4869-80.

64. Dvorak P, Hlavac V, Mohelnikova-Duchonova B, et al. Downregulation of ABC transporters in non-neoplastic tissues confers better prognosis for pancreatic and colorectal cancer patients. J Cancer 2017;8:1959-71.

65. Zhou L, Wang H, Li Y. Stimuli-responsive nanomedicines for overcoming cancer multidrug resistance. Theranostics 2018;8:1059-74.

66. Taipale J, Chen JK, Cooper MK, et al. Effects of oncogenic mutations in Smoothened and Patched can be reversed by cyclopamine. Nature 2000;406:1005-9.

67. Liu M, Zhang W, Tang W, et al. Isocyclopamine, a novel synthetic derivative of cyclopamine, reverts doxorubicin resistance in MCF7/ADR cells by increasing intracellular doxorubicin accumulation and downregulating breast cancer stem-like cells. Tumor Biol 2016;37:1919-31.

68. Ji RC. Hypoxia and lymphangiogenesis in tumor microenvironment and metastasis. Cancer Lett 2014;346:6-16.

69. Hu YL, DeLay M, Jahangiri A, et al. Hypoxia-induced autophagy promotes tumor cell survival and adaptation to antiangiogenic treatment in glioblastoma. Cancer Res 2012;72:1773-83.

70. Semenza GL. Targeting HIF-1 for cancer therapy. Nat Rev Cancer 2003;3:721-32.

71. Milosevic M, Warde P, Ménard C, et al. Tumor hypoxia predicts biochemical failure following radiotherapy for clinically localized prostate cancer. Clin Cancer Res 2012;18:2108-14.

72. Meijer TW, Kaanders JH, Span PN, et al. Targeting hypoxia, HIF-1, and tumor glucose metabolism to improve radiotherapy efficacy. Clin Cancer Res 2012;18:5585-94.

73. Horsman MR, Mortensen LS, Petersen JB, et al. Imaging hypoxia to improve radiotherapy outcome. Nat Rev Clin Oncol 2012;9:674-87. 
74. Yang G, Gong H, Qian X, et al. Mesoporous silica nanorods intrinsically doped with photosensitizers as a multifunctional drug carrier for combination therapy of cancer. Nano Res 2015;8:751-64.

75. Song G, Chen Y, Liang C, et al. Catalase-loaded TaOx nanoshells as bio-nanoreactors combining high-z element and enzyme delivery for enhancing radiotherapy. Adv Mater 2016;28:7143-8.

76. Zhang Y, Heym B, Allen B, et al. The catalase-peroxidase gene and isoniazid resistance of Mycobacterium tuberculosis. Nature 1992;358:591-3.

77. Aebi H. Catalase in vitro. Methods Enzymol 1984;105:121-6.

78. Caruso F, Trau D, Möhwald H, et al. Enzyme encapsulation in layer-by-layer engineered polymer multilayer capsules. Langmuir 2000;16:1485-8.

79. Liu Y, Du J, Yan M, et al. Biomimetic enzyme nanocomplexes and their use as antidotes and preventive measures for alcohol intoxication. Nat Nanotechnol 2013;8:187-92.

80. Chen $\mathrm{H}$, Tian $\mathrm{J}, \mathrm{He} \mathrm{W}$, et al. $\mathrm{H} 2 \mathrm{O} 2$-activatable and $\mathrm{O} 2$-evolving nanoparticles for highly efficient and selective photodynamic therapy against hypoxic tumor cells. $J$ Am Chem Soc 2015;137:1539-47.

81. Khau T, Langenbach SY, Schuliga M, et al. Annexin-1 signals mitogen-stimulated breast tumor cell proliferation by activation of the formyl peptide receptors (FPRs) 1 and 2. FASEB J 2011;25:483-96.

82. Snapkov I, Öqvist CO, Figenschau Y, et al. The role of formyl peptide receptor 1 (FPR1) in neuroblastoma tumorigenesis. BMC Cancer 2016;16:490.

83. Wong DY, Yeo CH, Ang WH. Immuno-chemotherapeutic platinum(IV) prodrugs of cisplatin as multimodal anticancer agents. Angew Chem Int Ed Engl 2014;53:6752-6.

84. Kim SD, Lee HY, Shim JW, et al. A WKYMVm-containing combination elicits potent anti-tumor activity in heterotopic cancer animal model. PLoS One 2012;7:e30522.

85. Gong G, Xu Y, Zhou Y, et al. Molecular switch for the assembly of lipophilic drug incorporated plasma protein nanoparticles and in vivo image. Biomacromolecules 2012;13:23-8.

86. Wang W, Huang Y, Zhao S, et al. Human serum albumin (HSA) nanoparticles stabilized with intermolecular disulfide bonds. Chem Commun 2013;49:2234-6.

87. Traverso N, Ricciarelli R, Nitti M, et al. Role of glutathione in cancer progression and chemoresistance. Oxid Med Cell Longev 2013;2013:972913.

88. Chen Y, Zhang M, Jin H, et al. Prodrug-like, PEGylated protein toxin trichosanthin for reversal of chemoresistance. Mol Pharm 2017;14:1429-38.

89. Han EK, Gehrke L, Tahir SK, et al. Modulation of drug resistance by alpha-tubulin in paclitaxel-resistant human lung cancer cell lines. Eur J Cancer 2000;36:1565-71.

90. Niazi M, Zakeri-Milani P, Najafi Hajivar S, et al. Nano-based strategies to overcome p-glycoprotein-mediated drug resistance. Expert Opin Drug Metab Toxicol 2016;12:1021-33.

91. Ueda K, Taguchi Y, Morishima M. How does P-glycoprotein recognize its substrates? Semin Cancer Biol 1997;8:151-9.

92. Fang EF, Zhang CZY, Zhang L, et al. Trichosanthin inhibits breast cancer cell proliferation in both cell lines and nude mice by promotion of apoptosis. PLoS One 2012;7:e41592.

93. Shi WW, Wong KB, Shaw PC. Structural and functional investigation and pharmacological mechanism of trichosanthin, a type 1 ribosome-inactivating protein. Toxins (Basel) 2018;10:335.

94. Liang J, Zeng F, Zhang M, et al. Green synthesis of hyaluronic acid-based silver nanoparticles and their enhanced delivery to CD44+ cancer cells. RSC Adv 2015;5:43733-40.

95. Kim M-H, Billiar TR, Seol D-W. The secretable form of trimeric TRAIL, a potent inducer of apoptosis. Biochem Biophys Res Commun 2004;321:930-5

96. Walczak H, Miller RE, Ariail K, et al. Tumoricidal activity of tumor necrosis factor-related apoptosis-inducing ligand in vivo. Nat Med 1999;5:157-63.

97. Vrielink J, Heins MS, Setroikromo R, et al. Synthetic constrained peptide selectively binds and antagonizes death receptor 5. FEBS J 2010;277:1653-65.

98. Ivanov VN, Bhoumik A, Ronai Ze. Death receptors and melanoma resistance to apoptosis. Oncogene 2003;22:3152-61.

99. Fan QL, Zou WY, Song LH, et al. Synergistic antitumor activity of TRAIL combined with chemotherapeutic agents in A549 cell lines in vitro and in vivo. Cancer Chemother Pharmacol 2005;55:189-96.

100. Wang S, Ren W, Liu J, et al. TRAIL and doxorubicin combination induces proapoptotic and antiangiogenic effects in soft tissue sarcoma in vivo. Clin Cancer Res 2010;16:2591-604.

101. Singh TR, Shankar S, Chen X, et al. Synergistic interactions of chemotherapeutic drugs and tumor necrosis factor-related apoptosisinducing ligand/Apo-2 ligand on apoptosis and on regression of breast carcinoma in vivo. Cancer Res 2003;63:5390-400.

102. Orth M, Metzger P, Gerum S, et al. Pancreatic ductal adenocarcinoma: biological hallmarks, current status, and future perspectives of combined modality treatment approaches. Radiat Oncol 2019;14:141.

103. Mackey JR, Mani RS, Selner M, et al. Functional nucleoside transporters are required for gemcitabine influx and manifestation of toxicity in cancer cell lines. Cancer Res 1998;58:4349-57.

104. Damaraju VL, Damaraju S, Young JD, et al. Nucleoside anticancer drugs: the role of nucleoside transporters in resistance to cancer chemotherapy. Oncogene 2003;22:7524-36.

105. Spratlin J, Sangha R, Glubrecht D, et al. The absence of human equilibrative nucleoside transporter 1 is associated with reduced survival 
in patients with gemcitabine-treated pancreas adenocarcinoma. Clin Cancer Res 2004;10:6956-61.

106. Vinay DS, Ryan EP, Pawelec G, et al. Immune evasion in cancer: Mechanistic basis and therapeutic strategies. Semin Cancer Biol 2015;35:S185-98.

107. Cullis J, Siolas D, Avanzi A, et al. Macropinocytosis of nab-paclitaxel drives macrophage activation in pancreatic cancer. Cancer Immunol Res 2017;5:182-90.

108. Altieri DC. Survivin, cancer networks and pathway-directed drug discovery. Nat Rev Cancer 2008;8:61-70.

109. Reichert S, Rödel C, Mirsch J, et al. Survivin inhibition and DNA double-strand break repair: a molecular mechanism to overcome radioresistance in glioblastoma. Radiother Oncol 2011;101:51-8.

110. Rödel F, Reichert S, Sprenger T, et al. The role of survivin for radiation oncology: moving beyond apoptosis inhibition. Curr Med Chem 2011;18:191-9.

111. Chanmee T, Ontong P, Konno K, et al. Tumor-associated macrophages as major players in the tumor microenvironment. Cancers (Basel) 2014;6:1670-90.

112. Hayashi N, Kataoka H, Yano S, et al. A novel photodynamic therapy targeting cancer cells and tumor-associated macrophages. Mol Cancer Ther 2015;14:452-60.

113. Kang XJ, Wang HY, Peng HG, et al. Codelivery of dihydroartemisinin and doxorubicin in mannosylated liposomes for drug-resistant colon cancer therapy. Acta Pharmacol Sin 2017;38:885-96.

114. Condeelis J, Pollard JW. Macrophages: obligate partners for tumor cell migration, invasion, and metastasis. Cell 2006;124:263-6.

115. Mantovani A, Sozzani S, Locati M, et al. Macrophage polarization: tumor-associated macrophages as a paradigm for polarized M2 mononuclear phagocytes. Trends Immunol 2002;23:549-55.

116. Suzman DL, Antonarakis ES. Castration-resistant prostate cancer: latest evidence and therapeutic implications. Ther Adv Med Oncol 2014;6:167-79.

117. Meng Z, Wei F, Wang R, et al. NIR-laser-switched in vivo smart nanocapsules for synergic photothermal and chemotherapy of tumors. Adv Mater 2016;28:245-53.

118. Chen W, Ouyang J, Liu H, et al. Black phosphorus nanosheet-based drug delivery system for synergistic photodynamic/photothermal/ chemotherapy of cancer. Adv Mater 2017;29:1603864.

119. Chen $\mathrm{Q}$, Feng $\mathrm{L}$, Liu J, et al. Intelligent albumin- $\mathrm{MnO} 2$ nanoparticles as $\mathrm{pH}-\mathrm{H} 2 \mathrm{O} 2$-responsive dissociable nanocarriers to modulate tumor hypoxia for effective combination therapy. Adv Mater 2016;28:7129-36.

120. Kolokythas G, Daniilides K, Pouli N, et al. Design, synthesis, and cytotoxic activity evaluation of new linear pyranoxanthone aminoderivatives. $J$ Heterocycl Chem 2011;48:927-35.

121. Wang QL, Li J, Li XD, et al. An efficient direct competitive nano-ELISA for residual BSA determination in vaccines. Anal Bioanal Chem 2017;409:4607-14.

122. Gough JE, Scotchford CA, Downes S. Cytotoxicity of glutaraldehyde crosslinked collagen/poly(vinyl alcohol) films is by the mechanism of apoptosis. J Biomed Mater Res 2002;61:121-30.

123. White K, Bruckner JV, Guess WL. Toxicological studies of 2-mercaptoethanol. J Pharm Sci 1973;62:237-41.

124. Gong G, Xu Y, Zhou Y, et al. Molecular switch for the assembly of lipophilic drug incorporated plasma protein nanoparticles and in vivo image. Biomacromolecules 2012;13:23-8.

125. Kuzu OF, Toprak M, Noory MA, et al. Effect of lysosomotropic molecules on cellular homeostasis. Pharmacol Res 2017;117:177-84.

126. Elzoghby AO, Abdelmoneem MA, Hassanin IA, et al. Lactoferrin, a multi-functional glycoprotein: active therapeutic, drug nanocarrier \& targeting ligand. Biomaterials 2020;263:120355.

127. Abdelmoneem MA, Mahmoud M, Zaky A, et al. Dual-targeted casein micelles as green nanomedicine for synergistic phytotherapy of hepatocellular carcinoma. J Control Release 2018;287:78-93. 